\title{
A Smart Quota System for Rationing Power in African Developing Countries
}

\author{
Eliel Keelson \\ Computer Engineering, \\ Kwame Nkrumah Univ. of \\ Science and Tech., Ghana.
}

\author{
Isaac Ghansah \\ Computer Science, \\ California State University \\ Sacramento, U.S.A
}

\author{
K.O. Boateng \\ Computer Engineering, \\ Kwame Nkrumah Univ. of \\ Science and Tech., Ghana.
}

\begin{abstract}
Electrical energy (electricity) has become an indispensable asset in building sustainable economies and reducing poverty. For such reasons many countries have embarked on various electrification projects, from urban areas to rural areas. However, these projects would not achieve the earlier stated objectives where there is unreliable supply of electric power. Most developing countries especially in Africa are often plagued with power crises. These crises are often as a result of energy constraints and/or generation capacity constraints. Various energy efficiency/demand side management schemes have been implemented to properly ration power. These schemes range from rotational load shedding programs to energy quota systems, with the latter presenting more advantages than the former. Energy quota systems were first known to be only effective in rationing power in energyconstrained environments. However, the advent of smart metering technology has also proved this scheme also effective in capacity-constrained environments. Despite the many advantages of this scheme over rotational load shedding programs, most developing countries in Africa such as Ghana and Nigeria, still use the latter as the only means of rationing power. In this paper, the advantages of energy quota systems over load shedding programs are brought to light, international best practices of this scheme are also discussed and we propose a model energy quota system using smart energy meters. Additionally we propose a design aimed at retrofitting existing (non-smart) meters and converting them into smart meters for developing countries in Africa. The proposed model does not require the replacement of old standalone energy meters.
\end{abstract}

\section{General Terms}

Power Rationing Schemes, Smart Metering Systems

\section{Keywords}

Power Rationing Schemes, Quota System, Smart Meter, Africa, developing countries

\section{INTRODUCTION}

The importance of electricity in this present age cannot be overemphasized and this is evidenced by the constant growing demand for it [1]. The Energy Information Administration (EIA) has predicted that this incessant growth in demand would hang around for the next few decades [2]. This is partly due to increasing human population and economic development [3]. To meet the growing demand for electrical energy, most countries have had to increase their generation capacities and improve their electrification network to minimize losses. To do this there has been the need to dedicate more resources to this sector. These resources include financial resources, energy sources, labour, metering technology, technical equipment, organizational structures and policies, among others.

Despite the urge to stay ahead of the demand curve, many countries have had shortages in some of the above listed resources making it difficult to meet the surging demand [4]. For example, most developing African countries such as Kenya, Tanzania, Nigeria and Cameroon are highly dependent on hydropower hence they face shortages in energy during severe droughts. Other developing countries in Africa such as Ghana and Uganda also lack capital to increase their generation capacities [5]. Notwithstanding the various degrees of supply-side management, these constraints have plunged these African countries into multiple prolonged seasons of power crises [4].

Confronted with this plague there has been the need to ration this scarce commodity by implementing several demand-side management strategies [5]. The most common strategy used in Africa is rotational load shedding programs, which is often known as blackouts [4]. This is often used because it is simpler to implement as compared to quota systems which often requires some preliminary structures. However, no matter how blackouts are coordinated, they present lesser advantages than quota systems [6]. A critical look at blackouts as a scheme of rationing power would reveal that they are inefficient and are not rolled out in a socially equitable way. With such a scheme, developing countries would hardly make any sufficient saves thus making the dream of a future of little or no power crises unattainable.

There is therefore an immediate necessity to improve or replace this scheme with an efficient power rationing scheme. The new scheme should not only be rolled out in a socially equitable way but should also be done in a manner that prepares the grounds for a future of little or no power crises. Such a scheme should also inculcate in every consumer a lifestyle of efficient energy use and conservation [7]. The quota system of rationing power has been proven without fail to have all the above characteristics [5][6].

In this paper we bring to light the various types of power shortages and how they can be addressed using a quota system of rationing power. In section 2 of this paper, concise explanation is given on the types of power shortages. In section 3, we juxtapose the two common power rationing schemes in an attempt to settle for one that best suits developing African countries. Section 4 presents international best practices of the quota system as implemented in Brazil. Section 5 highlights proposed methods of rolling out the quota system in both energy-and-capacity constrained countries using a smart meter. In section 6, a design of a smart retrofitted meter aimed at usage in developing countries is proposed. Finally the conclusion is given in section 7 . 


\section{POWER SHORTAGES}

A power shortage may be described as a deficit in a power supply making it impossible for utility companies to continuously meet the demand of their customers. Severe cases of power shortages often result in power crises. There are three types of power shortages; they are energy shortages, capacity shortages and a merge of energy-and-capacity shortages [6]. All the various reasons for power shortages could be placed under one of these types.

An energy shortage is the case where the power system can only supply power at a given instant or over a given period of time. That is to say that it would run out of energy resources if it is left to continuously run. Nearly all developing African countries that are heavily dependent on hydropower suffer energy shortages during droughts. So it is with any country whose power system runs short of its primary fuel [6].

A capacity shortage on the other hand, is a shortage in which the power system, no matter the copiousness of its energy resources, is physically inadequate to meet its peak demand. However, it can meet the demand during off-peak hours. Most power generation stations that are either underfunded or lack the optimum generation/transmission infrastructure often suffer this shortage [6].

A merge of energy-and-capacity shortages is a combination of the above mentioned shortages. The table below shows some African developing countries and periods in which they had power shortages.

Table 1. Notable Power Shortages in Africa [5]

\begin{tabular}{|l|l|l|}
\hline Country & Period & Type Of Shortage \\
\hline Ethiopia & $2006-$ date & Capacity Shortage \\
\hline Ghana & $2006-$ date & Capacity Shortage \\
\hline Kenya & 2001 & Energy Shortage \\
\hline Rwanda & $2006-$ date & Capacity Shortage \\
\hline $\begin{array}{l}\text { South } \\
\text { Africa }\end{array}$ & 2008 & Energy-and-Capacity Shortage \\
\hline Tanzania & 2001 & $\begin{array}{l}\text { Energy Shortage, } \\
\text { Energy-and-Capacity Shortage }\end{array}$ \\
\hline Uganda & 2006 & Energy-and Capacity Shortage \\
\hline
\end{tabular}

\section{POWER RATIONING SCHEMES}

Due to these shortages, many affected countries have had to embark on power rationing schemes. These schemes are implemented with the main objective of reasonably managing the limited power supply to avoid a complete shutdown of the power system. The two most common power rationing schemes are rotational load shedding and quota systems [6][7].

Rotational load shedding (blackouts) involve the shutting down of a feeder that distributes electricity to a specific area over a period of time. In severe shortages more than one feeder would be shutdown thus affecting wider regions over longer periods of time. In well managed shortages, a program/timetable is provided to consumers to help them know when their areas would be affected by blackouts [8]. This is the most used scheme by developing countries in Africa [4].

Quota systems on the hand are systems in which consumers are compelled to reduce their consumption to a specified amount over a particular period of time. They are often implemented incorporating price signals where consumers who violate the defined baseline are penalized whiles those who are overachievers are rewarded [5][6].
Blackouts are relatively cheaper and easier to roll out as compared to quota systems [9]. With quota systems there is the need to install structures to set quotas and policies as well as check out for violators and overachievers. Despite the initial hustle needed in the setup of a quota system which incorporates market signals, its benefits far outweighs that of rotational load shedding programs [6]. In the next few subsections the paper highlights some of these benefits.

\subsection{Social Equitability}

With quota systems consumers within the same category are each given a quota of the same magnitude. Each consumer has full control of his quota hence he is never denied of power even if his neighbours fail to efficiently use or conserve energy thus quickly consuming their quota. This is not the case with blackouts. When blackouts are rolled out, all consumers within the affected area are denied of electricity; not considering their various dispositions as to whether they efficiently use energy (conserve energy) or not.

\subsection{Lessens Load Shedding}

Unlike rotational load shedding programs, quota systems do not require wide/massive load shedding since consumers are only denied of power or penalized when they transgress their specified quota. This assures consumers of reliable power supply.

\subsection{Energy Conservation Lifestyle}

Quota systems that are implemented in tandem with penalties and bonuses often motivate consumers to alter their consumption lifestyle in order to manage their given quota. With programmed blackouts, since consumers are well informed of the periods of no power, they simply adjust their schedule of electricity usage. It can therefore be inferred that more energy is conserved when quota systems are implemented. This helps a country to increase its energy reserves thus preparing them for a future of little or no power crisis.

The above mentioned comparisons between the two power rationing schemes are summarized in Table 2.

The decision of which power rationing scheme to carry out must be guided by the features listed in Table 2 below. From the table it is clear that it is more reasonable to ration power using a quota system than rolling blackouts.

Table 2. Comparison between Rotational Load Shedding and Quota Systems

\begin{tabular}{|l|c|c|}
\hline \multicolumn{1}{|c|}{ FEATURE } & BLACKOUT & $\begin{array}{c}\text { QUOTA } \\
\text { SYSTEM }\end{array}$ \\
\hline Cost effective & Yes & Yes \\
\hline $\begin{array}{l}\text { Easily and quickly } \\
\text { scalable }\end{array}$ & Yes & No \\
\hline Social Equitability & No & Yes \\
\hline $\begin{array}{l}\text { Preparation for a future of } \\
\text { little/no power crises }\end{array}$ & No & Yes \\
\hline $\begin{array}{l}\text { Cultivation of energy } \\
\text { conservation lifestyle }\end{array}$ & No & Yes \\
\hline $\begin{array}{l}\text { Reduction in mass/wide } \\
\text { load shedding }\end{array}$ & No & Yes \\
\hline $\begin{array}{l}\text { Assurance of reliable } \\
\text { energy supply }\end{array}$ & No & Yes \\
\hline $\begin{array}{l}\text { Consumer control over } \\
\text { consumption }\end{array}$ & &
\end{tabular}




\section{QUOTA SYSTEM IN BRAZIL}

In this section, the paper shows how quota systems could be rolled out to enjoy the above stated benefits. It does this by describing how it was successfully implemented in Brazil.

Brazil was heavily hydro-dependent in the year 2001, just like most African developing countries are currently [6][10]. Having suffered vagaries of rainfall in the previous years coupled with the wait-and-see canker, they were plunged into a grave period of power crisis which lasted from March 2001 till February 2002. This called for the implementation of a stringent power rationing scheme. After careful deliberations on the two common schemes, in May 2001 they chose and implemented the quota system incorporating price signals (bonuses and penalties) [6].

In rolling out this system, the various classes of consumers were identified and each consumer was given a quota of energy. This quota was often $20 \%$ less of their average consumption during the same period in the previous year. So for example, a consumer who consumed 100 Kilowatt hours in June 2000 was now given a quota of 80 Kilowatt hours for June 2001. This percentage was however different for other classes of consumers. Below is a table showing the initial quotas allotted to the different classes of consumers.

Table 3. Initial Quota Allocation by Consumer Group [6]

\begin{tabular}{|l|l|}
\hline CLASS OF CONSUMER & QUOTA \\
\hline Residential < 100 kWh/month & $100 \%$ \\
\hline Residential > 100 kWh/month & $80 \%$ \\
\hline $\begin{array}{l}\text { Low-voltage industrial, commercial } \\
\text { and services }\end{array}$ & $80 \%$ \\
\hline $\begin{array}{l}\text { High voltage industrial, commercial } \\
\text { and services }\end{array}$ & $\begin{array}{l}70 \% \text { to } \\
\text { according to activity }\end{array}$ \\
\hline Rural & $90 \%$ \\
\hline $\begin{array}{l}\text { Other consumers (mostly } \\
\text { government) }\end{array}$ & $65 \%$ \\
\hline
\end{tabular}

Consumers who transgressed their given quota were penalized. The magnitude of the penalties was dependent on how far he had crossed the quota and how many times he had done so. Penalties ranged from several days of power interruption to payment of higher tariffs than the norm. Monies paid by offenders were often used to incentivize overachievers. Consumers who were not satisfied with their given quotas could apply for higher quotas at higher rates. Payments for the extra quotas were given to distribution companies to help purchase extra power supplies from generating companies [6]. This scheme is therefore founded on the premises of the consumer's inclination to either conserve energy or pay extra for power without necessarily rolling out blackouts or brownouts.

This power rationing scheme was very successful and yielded 20-25 percent reduction in consumption as depicted in Table 4. It was however noticed that more than 60 percent of this reduction was contributed by low-income consumers. This could be attributed to the fact that they were highly motivated by the bonuses awarded them for consuming below the baseline. It also meant that in this scheme the poor is protected from high tariffs. This success also proved that this rationing scheme is feasible and scalable.
Table 4. Average Energy Saved In the Various Regions of Brazil [6]

\begin{tabular}{|l|c|c|}
\hline \multirow{2}{*}{ REGION } & \multicolumn{2}{|c|}{$\begin{array}{c}\text { SAVED ENERGY \% OF } \\
\text { CORRESPONDING LOAD IN }\end{array}$} \\
\cline { 2 - 3 } & $\mathbf{2 0 0 0}$ & $\mathbf{2 0 0 1}$ \\
\hline North & $18.3 \%$ & $24.6 \%$ \\
\hline Northeast & $19.5 \%$ & $20.7 \%$ \\
\hline Southeast/Center-West & $19.8 \%$ & $21.2 \%$ \\
\hline
\end{tabular}

The Brazilian implementation of the Quota System incorporating price signals has been reckoned as an international best practice of rationing power [5][6][11]. Developing countries in Africa can learn a lot from this implementation and possibly do same or better. It should however be noted that the Brazilian strategy was purely targeted toward an energy-constrained environment. In capacity-constrained environments, where there is the need to ration power especially at critical peak hours of the day, this application may not work [6]. There would be the need to augment this scheme before it can produce the same successful results.

In the next section we propose a quota system that is implemented using a smart meter. This system incorporates some of the strategies used in Brazil as well as adding smart meter technology to cater for both energy-and-capacityconstrained environments.

\section{A SMART QUOTA SYSTEM}

In the previous section, we explained how the quota system was successfully implemented in Brazil. However, it must be stated that the strategy used was aimed at energy-constrained areas, as was the case in Brazil, and that the same strategy would not be very beneficial in capacity-constrained areas [6]. In this section we suggest a quota system that can be implemented using a smart meter which would effectively ration power in any type of shortage.

A smart meter is a metering device that records electrical consumption data and periodically transmits the recorded data to utilities in real-time or near real-time [12]. Such data helps generation and distribution companies to match demand with supply. Equipped with this two-way communication ability, utilities are able to communicate to consumers on issues regarding consumption, tariffs, load shedding exercises, energy conservation tips and maintenance exercises [13]. These benefits together with remote connection/disconnection and remote power quality monitoring reduce the operational costs of utilities. Also real-time electrical usage data help consumers cultivate an energy saving lifestyle [14].

In Brazil's implementation of the quota system there was no smart metering technology used. This implied that Time-ofUse (TOU) tariffs were not used. Time-of-Use tariffs are tariffs which are not fixed all through the hours of the day but vary at different hours of the day to reflect the current price of electricity. This is very necessary in rationing power in a capacity-constrained environment where generation companies find it difficult to meet the demand at peak hours of the day [6]. By using the smart meter utility companies can implement and communicate TOU tariffs to consumers via their smart meters. Consumers can then decide to alter their consumption lifestyle to conserve energy during peak hours of the day since tariffs would be higher during those periods. 
The key element of the quota system is the quota. No smart metering technology also implied that quotas were communicated to the consumer through other means than the meter. If these communication/delivery methods are not automated they are bound to be subject to human errors. The inclusion of smart meters in this system would help utilities communicate each consumer's quota via their meters even months ahead of the quota period. These early notices would help consumers psyche themselves to manage their given quota.

Also in capacity-constrained areas where TOU tariffs are not used quotas can still be used to reduce peak demand. These quotas should cover shorter periods; a week, a day or a number of hours which would reflect either peak periods or non-peak periods. It would be difficult to communicate these ever-varying quotas without a smart meter.

Likewise, the absence of smart meter technology in Brazil meant that violators and overachievers were only identified at the end of the quota period when meters were manually read. With the smart meter, utilities can easily identify violators and overachievers on a daily or hourly basis through remote meter reading. Rewards and penalties would be given out earlier than it was the norm in Brazil. If violators are identified and notified earlier than waiting till the end of the period, they would transgress less beyond their given quota. Violators could also be remotely disconnected and reconnected when penalties are paid. This remote controlled feature of the smart meter reduces the operational cost of running the quota system.

By combining the strategies used in Brazil with the above suggested measures incorporating the smart meter, the quota system of rationing power can be used effectively and efficiently for all types of shortages.

\section{A SMART RETROFITTED METER}

Despite the appealing benefits presented by the smart meter, most developing countries in Africa still use standalone metering systems; that have no communication ability [15]. This paper suggests a simple retrofit design that can be added to such meters which would provide them with smart metering capabilities. This retrofit uses general packet radio service (GPRS) to communicate data to and from utilities. This data service was selected because it works on a Global System for Mobile Communications (GSM), which is the most common means of communication in Africa [15]. Figure 1 and Figure 2 are diagrams showing the basic design of the retrofit.

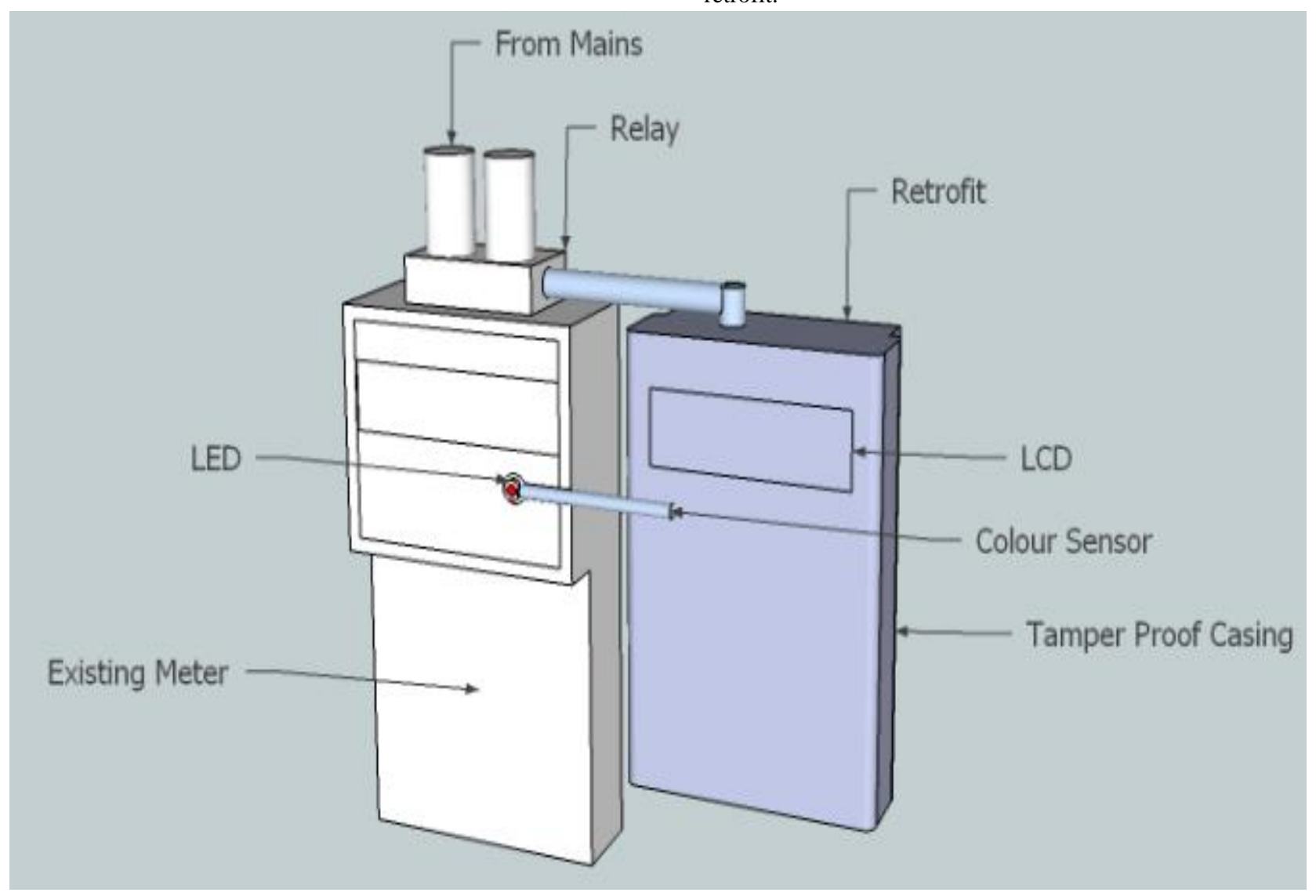

Fig. 1: A block diagram showing the connection between the existing meter and the retrofit [15] 


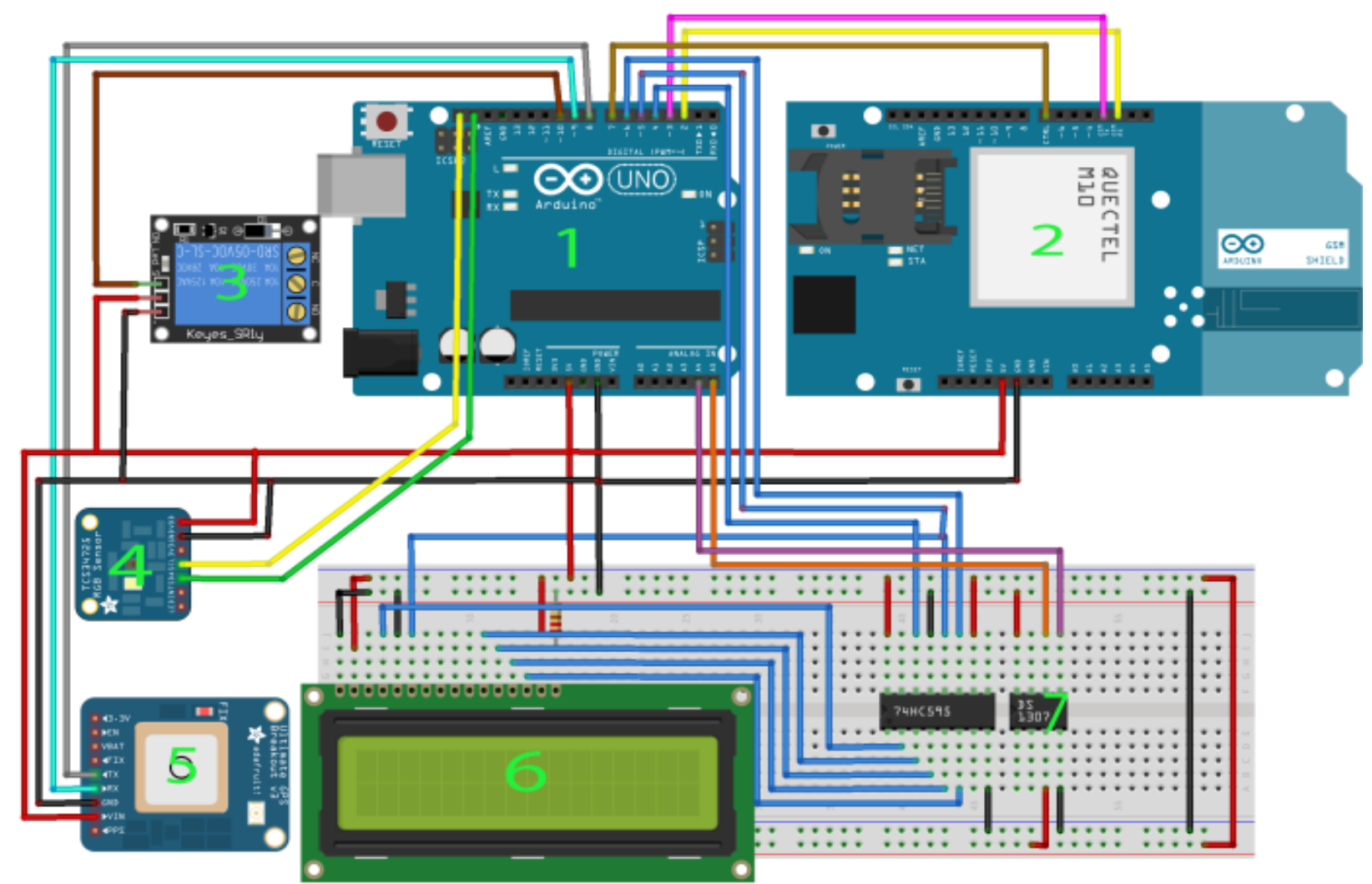

fritzing

Fig. 2: A breadboard diagram showing the interconnection of the major components of the retrofit

The retrofit is made of seven main parts as depicted in figure 2 . These components and their basic functions are stated in the table below, they are numbered in the same order as shown in Figure 2.

Table 5. Major components of the retrofit and their functions

\begin{tabular}{|c|c|c|}
\hline & Component & Function \\
\hline 1 & $\begin{array}{l}\text { Arduino Uno } \\
\text { Microcontroller }\end{array}$ & $\begin{array}{l}\text { A microcontroller board } \\
\text { programmed to handle the logic } \\
\text { process }\end{array}$ \\
\hline 2 & $\begin{array}{l}\text { Arduino GSM } \\
\text { Shield }\end{array}$ & $\begin{array}{l}\text { For data communication via a } \\
\text { GSM/GPRS modem }\end{array}$ \\
\hline 3 & Keyes Relay & $\begin{array}{l}\text { Used for remote } \\
\text { connection/disconnection. In } \\
\text { practice it is used to drive a second } \\
\text { relay of a higher rating. }\end{array}$ \\
\hline 4 & $\begin{array}{l}\text { TCS34725 RGB } \\
\text { Colour Sensor }\end{array}$ & $\begin{array}{l}\text { Used here as a coupler which } \\
\text { detects consumption. It does this by } \\
\text { detecting a colour change from a } \\
\text { light emitting diode (LED) which } \\
\text { blinks each time a defined unit of } \\
\text { energy is consumed. }\end{array}$ \\
\hline 5 & $\begin{array}{l}\text { Adafruit Ultimate } \\
\text { GPS Breakout }\end{array}$ & $\begin{array}{l}\text { Used to detect the geographical } \\
\text { position of the existing meter. This } \\
\text { information is sent together with } \\
\text { consumption data to the utility. }\end{array}$ \\
\hline 6 & $\begin{array}{l}\text { Liquid Crystal } \\
\text { Display(LCD) }\end{array}$ & $\begin{array}{l}\text { Used to display consumption data, } \\
\text { tariffs, conservation tips and other } \\
\text { announcements for the consumer's } \\
\text { notice. }\end{array}$ \\
\hline 7 & $\begin{array}{l}\text { DS1307 Real } \\
\text { Time Clock }\end{array}$ & $\begin{array}{l}\text { Provides real-time for programming } \\
\text { logic as well as logging data. }\end{array}$ \\
\hline
\end{tabular}

In summary this retrofit is connected to an existing meter using a colour sensor and a relay which is connected to the mains. The colour sensor acts as a coupler which detects pulses from an LED on the existing meter. This LED blinks each time a defined quantity of energy is consumed; say once every kilowatt hour. Upon detection, the colour sensor triggers the microcontroller unit (MCU) which processes, displays and stores it as consumption data. This data is sent to the utility company at regular intervals via the GSM/GPRS modem. The retrofit also receives tariff updates and notifications from the utility which it displays on the LCD for the consumer. In cases of disconnection/reconnection, a message is received from the utility and processed by the MCU, which in turn would instruct the relay to carry out the requested action [15].

With this retrofit, developing countries in Africa can have smart meters without replacing their old standalone meters. This would also enable them roll out the proposed smart quota system which effectively and efficiently rations power in both energy and capacity shortage environments in a socially equitable way.

The implementation of the proposed smart quota system in African developing countries would require close collaboration from the government, generation, transmission and distribution companies as well as experts and policymakers from the energy sector. The manner in which this scheme is implemented is highly dependent on the following factors:

1. Type of power shortage.

2. Average generation capacities of each generation company; at peak and non-peak periods 
3. Average cost of generation and distribution; at peak and non-peak period,

4. Rate of depletion of energy reservoirs.

5. Types of Load and its distribution

6. Demand growth rate

7. Rate of capacity addition

8. Pattern of Gross Domestic Product (GDP) growth

These factors would aid collaborators to critically assess the shortage and know how and when to act as well as identify key policies and regulatory framework needed to effectively rollout this scheme.

\section{CONCLUSION}

This paper highlights some important benefits of the quota system over rotational load shedding programs. By merging international best practices of this scheme with a proposed smart metering technology, it suggests ways in which developing countries in Africa can ration power in an effective manner no matter the type of shortage. To ensure that all customers have smart meters on their premises, we have presented a scheme of retrofitting existing standalone (non-smart) meters to turn them into smart meters at affordable costs. In future this retrofit model can be further developed and used as the basis of developing a smart grid for African developing countries.

\section{REFERENCES}

[1] "World Energy Consumption", Wikipedia, https://en.wikipedia.org/wiki/World_energy_consumptio n, June 2013

[2] Parliamentary Commissioner for the Environment - Te Kaitiaki Taiao a Te Whare Pāremata, "Smart Electricity Meters - How Households and the Environment can Benefit", Netherland, June 2009.

[3] Catherine Wolfram, Orie Shelef, and Paul Gertler, "How Will Energy Demand Develop in the Developing World?" pp. 1-5, January 2012.

[4] APR Energy, "A View on Global Energy - Africa Energy for Progress", APR Energy, LLC, 3600 Port Jacksonville Parkway, Jacksonville, FL 32226 USA, January 2013.

[5] Energy Sector Management Assistance Program (ESMAP), "Best Practices for Market-Based Power Rationing - Implications for South Africa", Briefing Note, South Africa, August 2011.
[6] Energy Sector Management Assistance Program (ESMAP), "Implementing Power Rationing in a Sensible Way - Lessons Learned and International Best Practices", Report 305/05, August 2005

[7] Energy Sector Management Assistance Program (ESMAP), "Implementing Energy Efficiency and Demand Side Management - South Africa's Standard Offer Model”, Briefing Note, South Africa, July 2011.

[8] "Rolling Blackout", Wikipedia, https://en.wikipedia.org/wiki/Rolling_blackout, September 2014

[9] Sara Bryan Pasquier, International Energy Agency, "Saving Electricity in a Hurry", Energy Efficiency Series, Information Paper, Update, pp. 15-35, 2011

[10] Energy Sector Management Assistance Program (ESMAP), "South Africa's Market Based Power Rationing Program", Low Carbon Growth Country Studies Program, Briefing Note, August 2010

[11] Luiz T.A. Maurer, Luiz A Barroso, "Electricity Auctions", An Overview of Efficient Practices, A World Bank Study, 2010

[12] Engr. Bilal Shahid, Zubair Ahmed, Adnan Faroqi, and Rao M.Navid-ur-Rehman "Implementation of Smart System Based on Smart Grid Smart Meter and Smart Appliances", 2012 International Conference on Smart Grid Systems (ICSGS 2012), IPCSIT vol.45 ,pp.1-5, 2012

[13] Tom Wilson, BSEE, Green and Healthy Homes, "Smart Grid \& Smart Meter Architecture", Wireless Safety Summit Washington DC, Oct. 5, 2011.

[14] A Joint Project of the EEI and AEIC Meter Committees, "Smart Meters and Smart Meter Systems: A Metering Industry Perspective", An EEI-AEIC-UTC White Paper, pp. 5-10 March 2011.

[15] Eliel Keelson, K.O. Boateng, Isaac Ghansah, "A Smart Retrofitted Meter for Developing Countries", International Journal for Computer Applications (0975 8887), Volume $90-N$, March 2014 